four years ago to compile a dictionary which should in some way serve, not only to fill the wants just pointed out, but also as a guide to appropriate names for new forms. A further use for such a list is suggested by a foreign term used in a recent government publication, and also in another sense in a somewhat earlier private paper by another writer.

The undersigned now wishes to appeal to all those interested in the advancement of the study of geomorphology, to aid in the preparation of this dictionary-already over three hundred terms have been catalogued-by sending to him the following data for any topographic term, in any language, which may be met with in the course of study or reading:

1. The new term, and the inventor or first user of it in the given sense.

2. The etymology of the term, if possible.

3. The publication, volume, page and year, where first used.

4. The original definition, preferably quoted.

5. The cited examples of the form or combination of forms to which the inventor, or first user, applied it.

The above need not be written on catalogue cards, but preferably should be typewritten. The latter is not at all a prime requisite, however.

Of course the contributors to the work will be given full credit for the aid they render. Letters should be addressed to

Cleveland Abbe, Jr.

1441 Florida Avenue, N. W., WAShington, D. C.

AMEBE FOR THE LABORATORY.

To the EDItor of Science: Just at this season many teachers of zoology are looking for Amœbæ for their students, and as I remember well the difficulty that is often experienced in securing them in considerable numbers and of good size, I venture to give a very simple method of obtaining them which I hit upon accidentally two years ago and have found highly satisfactory ever since; it is quite possible that this method is in use by others and it may be that it has been recorded, but if so it has escaped my notice. Two years ago while examining some insect eggs which were attached to the lily-pads on a pond on my summer place, I noticed numerous amœbæ. So I suggested to my laboratory assistant the following autumn that he get a considerable number of lily-pads and remove the slime which adheres to the under surface with a spatula and put it in a shallow glass aquarium containing water six or eight centimeters deep. This he did, placing the vessel near a window, and in a week or two the amœbæ were very large and abundant on the surface of the sediment at the bottom of the aquarium. We followed the same method this year with equally satisfactory results, so that I believe it to be as reliable as it is simple, and I would strongly recommend it to any one who has had trouble in securing this useful animal.

Boston UnIVERsity.

A. W. WEYsSe.

DO RHIZOPODS DIE A NATURAL DEATH?

To the Editor of Science: In various works on zoology and geology statements like the following are usually found, and, so far as I know, have never been questioned: $* * *$ in the oceans Globigerinæ live in countless numbers. Dying, their shells accumulate to form thick layers on the ocean bottom.'

We know that as a rule protozoa do not die a natural death, as that term is used in reference to higher animals. They subdivide and we have two protozoa, these subdivide and there are four, and so on to the end of time. The fact that Globigerinæ protect themselves with a shell which consists of a series of chambers does not prevent them from withdrawing from their shell for purposes of conjugation and reproduction somewhat as do the diatoms. I would be very much obliged if some reader of ScIEnce who has studied the habits of rhizopods would answer the question, given above, in the correspondence department of your journal. L. C. Wooster.

Department of Biology and Geology, State Normal School, Emporia, Kansas.

\section{BODY TEMPERATURE.}

To the Editor of Science: In Science for September 9, Mr. Woods Hutchinson requests references to articles dealing with body temperature. If he has not already seen the vol- 
ume, he will be interested in 'Principles of Animal Nutrition,' by H. P. Armsby, director of the Pennsylvania State Agricultural Experiment Station, which discusses this and related topics and summarizes a large amount of interesting information. The question is also taken up by Dr. Armsby in 'The Isodynamic Replacement of Nutrients,' ScIEnce, N. S., 18 (1903), No. 459, pp. 481-487.

Some experiments which have to do with temperature during fever with especial relation to the influence of the abnormal body condition on metabolism are summarized in Bulletin No. 45 of the Office of Experiment Stations, entitled 'A Digest of Metabolism Experiments.'

The Jahresbericht der Tier-Chemie contains numerous titles and abstracts of articles which deal with the question under consideration. The Department of Agriculture library contains a set of this journal, which can undoubtedly be found also in a number of other public or university libraries.

C. F. Langworthy.

Office of Experiment Stations, Department of Agriculture.

\section{MATHEMATICS AND METAPHYSICS.}

ON reading the interesting lecture of Professor Josiah Royce on 'The Sciences of the Ideal,' and learning that all leveling and serial relations come from the same root, one is reminded of the computer of the coast survey, who decided that $8 \times 8$ is not exactly 64 , but plus or minus a small quantity, according to the table of logarithms he used. If mathematics and metaphysics coalesce where shall we rest? Will our mathematicians become 'flabbier and flabbier'?

A. Hall.

October 10, 1904.

\section{SPECIAL ARTICLES.}

WHAT IS AN ELECTRIC CURRENT?*

'THE question of the day which seems to appeal most strongly to the physicist is: What is taking place in a metallic conductor on the terminals of some electrical source?

* Abstract from an address on 'Present Problems in Physics,' at the Congress of Arts and Science.
Rowland's rotating disk showed that a positively charged body moving in a positive direction, and a negatively charged body moving in an opposite direction, produce the same electromagnetic effects in the surrounding field.

Rutherford's work in deflecting the electrons of a radioactive body is in entire harmony with Rowland's result. Positively charged masses of radiant matter are deflected in the opposite direction from negatively charged matter, when acted upon by a magnetic field, the masses are, of course, moving in the same direction. These charged particles of moving matter are, in effect, superposed, or perhaps juxtaposed electric currents moving in the same direction. If either the $a$ or the $\beta$ particles could be reversed in direction, then the magnetic field would deflect them in the same direction. They would then each create the same external magnetic effects. They would then represent superposed currents of opposite sign, moving or flowing in opposite directions.

All of this means that a positive current of electricity flowing in a positive direction is not a negative current of electricity flowing in a negative direction. These two currents involve the motion of masses of matter in opposite directions. Do these currents co-exist in the conducting wire? Is a direct-current dynamo pouring oppositely moving electrons into the opposite ends of the conductor? After a few thousand years of continuous use, may it become clogged and lose in part its conductive properties, acquiring perhaps meanwhile radioactive properties?

Wheatstone made a famous experiment on the discharge of a Leyden jar, which was thought very instructive in his day. But did his contemporaries really learn the lesson which that experiment teaches. The sparks at the two gaps nearest the terminals of the conductor were formed before the central spark appeared. Have we not here evidence that the positive and negative currents, moving in opposite directions, begin at the opposite terminals, and only become superposed after an appreciable time interval?

In a Geissler tube having a length of about 